\title{
Emerging Role for Use of Liposomes in the Biopreservation of Red Blood Cells
}

\author{
Jelena L. Holovati ${ }^{a, b}$ Jason P. Acker ${ }^{a, b}$ \\ ${ }^{a}$ Department of Laboratory Medicine and Pathology, University of Alberta, \\ ${ }^{\mathrm{b}}$ Canadian Blood Services, Research and Development, Edmonton, AB, Canada
}

\section{Keywords}

Biopreservation - Storage $\cdot$ Blood .

Erythrocyte - Liposomes - Membrane - Cryopreservation . Hypothermia $\cdot$ Red blood cell

\section{Summary}

Biopreservation is the process of maintaining the integrity and functionality of cells held outside the native environment for extended storage times. The development of red blood cell (RBC) biopreservation techniques that maintain in vitro RBC viability and function represents the foundation of modern blood banking. The biopreservation of RBCs for clinical use can be categorized based on the techniques used to achieve biologic stability, including hypothermic storage and cryopreservation. This review will examine the emerging role of liposomes in the RBC biopreservation, including the incorporation of liposomes into RBC membranes as an effective approach for minimizing RBC hypothermic storage membrane lesion and use of liposomes as a permeabilization strategy for the intracellular accumulation of novel intracellular cryoprotectants. Integration of current biopreservation research with blood banking practices offers enormous potential for future improvements of safety and efficacy of RBC transfusion.

\section{Schlüsselwörter \\ Biologische Konservierung · Lagerung · Blut • \\ Erythrozyt · Liposomen - Membran · Kryokonservierung · Hypothermie · Rote Blutkörperchen}

\section{Zusammenfassung}

Als "biologische Konservierung" bezeichnet man den Prozess der Aufrechterhaltung der Zellintegriät und -funktion für einen gewissen Zeitraum außerhalb der «natürlichen Umgebung». Die Entwicklung von Techniken zur biologischen Haltbarmachung von Erythrozyten, welche die In-vitro-Aufrechterhaltung von Zellvitalität und -funktion beinhalten, stellen den Anfang moderner Blutbanken dar. Die biologische Konservierung von Erythrozyten für den klinischen Einsatz kann anhand der Techniken gegliedert werden, die für das Erreichen der biologischen Stabilität eingesetzt werden; das beinhaltet die hypotherme Lagerung und die Kryokonservierung. Diese Übersichtsarbeit beschreibt die neue Rolle von Liposomen bei der biologischen Konservierung von Erythrozyten, was einerseits die Aufnahme von Liposomen in die Erythrozytenmembran beinhaltet, wodurch aufgrund der hypothermen Lagerung erzeugte Membranschäden minimiert werden können. Andererseits können Liposomen für die Permeabilisierung der Zellmembran eingesetzt werden, was zur intrazellulären Anreicherung von neuen Kryoprotektiven genutzt werden kann. Die Integration der derzeitigen Forschung zur biologischen Konservierung in die bestehenden Techniken hat ein enormes Potential für zukünftige Verbesserungen der Sicherheit und Wirksamkeit von Bluttransfusionen.

\begin{tabular}{ll}
\hline KARGER & @ 2011 S. Karger GmbH, Freiburg \\
Fax +497614520714 & Accessible online at: \\
Information@Karger.de & www.karger.com/tmh \\
www.karger.com &
\end{tabular}




\section{Why Preserve Red Blood Cells?}

The development of red blood cell (RBC) biopreservation techniques that maintain in vitro $\mathrm{RBC}$ viability and function represents the foundation of modern blood banking. The major driving force in the field of RBC biopreservation is direct clinical need. $\mathrm{RBC}$ transfusions save lives by increasing RBC mass in patients with low oxygen-carrying capacity due to acute blood loss (traumatic/surgical hemorrhage), decreased RBC bone marrow production (leukemias), and decreased RBC survival (hemolytic anemias) [1]. Effective RBC preservation procedures that maintain the integrity and function of RBCs in vitro have made it possible for blood banks to perform various processes for the production of RBC units for transfusion, such as collection, controlled blood distribution, quality control, transmissible disease testing, compatibility matching and transport, all of which are needed to ensure a readily available and safe blood supply. Every year, millions of RBC units are transfused worldwide due to the application of biopreservation techniques to transfusion medicine.

\section{Approaches to Red Blood Cell Biopreservation}

\section{RBC Hypothermic Storage}

The earliest and most widely investigated approach to RBC biopreservation has been hypothermic storage at $1-6{ }^{\circ} \mathrm{C}$. This approach is based on the principle that biochemical processes and molecular reactions can be suppressed by reducing the storage temperature below physiological temperature, but above freezing temperature. Although hypothermic storage minimizes RBC injury, cellular metabolism is not completely suppressed at hypothermic temperatures, resulting in nutrient depletion and accumulation of cell wastes [2,3]. All the detrimental biochemical and biomechanical effects of in vitro RBC hypothermic storage can be summarized by the term 'hypothermic storage lesion'. There are many well-documented components of hypothermic storage lesion. A major element of hypothermic storage lesion that has been gaining more attention in recent studies is RBC membrane injury [4-8]. There is strong evidence in the current literature that $\mathrm{RBC}$ viability, defined by post-transfusion RBC survival, is closely related to the structural and metabolic status of the RBC membrane [4-10]. RBC membrane hypothermic storage lesion includes lipid loss through microvesiculation leading to a decrease in critical hemolytic volume of RBCs; an increase of internal RBC viscosity and progressive spheroechinocytosis; altered rheologic properties, such as RBC deformability, mechanical stability and adhesiveness; exposure of phosphatidylserine on the membrane surface; and decreased expression of CD47 antigen on the RBC surface [2, 4, 11-16].

Advances in hypothermic storage of RBCs were made in response to more detailed information on $\mathrm{RBC}$ hypothermic storage lesion through additive supplementation of the origi- nal citrate-glucose preservative solution $[17,18]$. Several different approaches were shown to be effective for improving the structural and metabolic status of the RBC membrane during hypothermic storage. An unexpected benefit of storing blood in the plastic bags made of polyvinyl chloride was the presence of leachable plasticizers that incorporate themselves into the RBC membrane, reducing membrane loss and hemolysis $[3,5,11,14,19]$. A similar effect was seen with the addition of mannitol and citrate present in additive solutions such as SAGM (saline-adenine-glucose-mannitol) and AS-3 $[20,21]$. Although the exact mechanism of action of these membrane stabilizers still remains to be elucidated, their use allowed extension of RBC hypothermic storage by reducing in vitro hemolysis [20, 21].

Although the supplementation of additive solutions has effectively extended the length of hypothermic storage, an increasing number of laboratory and observational studies correlating the transfusion of stored RBCs to detrimental clinical outcomes have focused attention on the quality of stored blood. It has been shown that the percentage of stored RBCs that circulate when transfused decreases with the duration of hypothermic storage in all current additive solutions $[2,5,18]$. In observational studies, transfusion of 'old' (compared with 'fresh') RBCs has been associated with increased risk of postoperative pneumonia [22], infection at any site [23] or multiple organ failure $[24,25]$, prolonged length of stay in the hospital [26] or the intensive care unit [27] and prolonged mechanical ventilation [28]. Furthermore, transfusion of hypothermically stored RBCs has been associated with proinflammatory and immunomodulatory effects and, ultimately, increased morbidity and mortality [29-33]. Biomechanical changes of the RBC membrane persist during the hypothermic storage period in current additive solutions, despite the restoration of ATP and the use of membrane stabilizers [2,11, 34]. As there is direct need and clinical benefit to improving RBC quality during hypothermic storage, new approaches to minimize RBC hypothermic storage lesion that focus on improving the state of RBC membrane warrant further study.

\section{RBC Cryopreservation}

Although hypothermic storage slows down the RBC biochemical processes that result in nutrient depletion and accumulation of cell wastes, cellular metabolism is not completely suppressed at these temperatures. There still exists a need for a preservation technology that not only delays the deterioration of quality, but fully preserves RBC viability and function for extended storage periods. Cryopreservation of RBCs for transfusion is one of the most important applications of cryobiology research. The idea of cryopreserving RBCs and storing them at ultra-low subzero temperatures so that all metabolic and biochemical reactions cease has been around for at least 150 years [35]. The major advances in RBC cryopreservation occurred in the 1950s and 1960s, with the development of clinically safe techniques for RBC freezing, storage, thaw- 
ing and post-thaw processing. In the early 1970s, Meryman and Hornblower [36] greatly simplified the Tullis continuousflow centrifugation process by freezing the RBC unit in the original collection bag and deglycerolizing by dilution with a series of saline solutions of gradually decreasing osmolality. This technique, using 40\% (wt/vol) glycerol in conjunction with slow cooling $\left(\sim 1{ }^{\circ} \mathrm{C} / \mathrm{min}\right)$, storage at $-80{ }^{\circ} \mathrm{C}$ and rapid thawing in a $37^{\circ} \mathrm{C}$ water bath, is still the clinical method of choice for RBC freezing in North America. In 1968 Rowe and colleagues [37] applied the kinetic approach first suggested by Luyet [35], and developed a low glycerol/rapid freeze technique for RBC cryopreservation which involves addition of low concentrations (15-20\%) of glycerol, rapid cooling $\left(<100{ }^{\circ} \mathrm{C} / \mathrm{min}\right)$ by immersion into liquid nitrogen, storage in liquid nitrogen $\left(-196{ }^{\circ} \mathrm{C}\right)$ or nitrogen vapor $\left(-165^{\circ} \mathrm{C}\right)$, with rapid thawing in a $42-45^{\circ} \mathrm{C}$ water bath. $\mathrm{RBCs}$ frozen by this method also met with clinical success and are still used routinely by European blood banks. These glycerol-based methods still remain the standard of practice for maintaining an adequate inventory of RBCs with unpredictable patient needs and logistical problems, although they remain labor-intensive and expensive procedures that result in RBCs with shorter post-transfusion in vivo survival [18, 38-42].

Improved clinical RBC cryopreservation will have to be driven by research in the cryobiology field. Integration of current cryobiology research with blood banking practices offers enormous potential for future improvements. As pointed out by Meryman [43], learning from nature's own laboratory is the key to future advances in the field of cryobiology. Examining the physiological and molecular adaptations of organisms able to withstand environmental stresses has recently lead to introduction of a whole new class of cryoprotectants nonpermeating intracellular cryoprotectants such as trehalose. Although trehalose posses many qualities that would make it an exceptional cryoprotectant, its full potential cannot be attained unless it is present on both sides of cell membrane [44-49]. As mammalian plasma membranes are inherently impermeable to trehalose, the utility of trehalose as a cryoprotectant lies in introducing an innovative approach that will successfully load trehalose to cell cyotosol with minimal cell injury.

\section{Emerging Role of Liposomes in the Red Blood Cell Biopreservation}

Since 2004, our research group has been investigating the use of liposomes to improve RBC biopreservation techniques, both relating to hypothermic storage and cryopreservation. Liposomes are synthetic, microscopic, spherical vesicles composed of one or more concentric lipid bilayers enclosing an equal number of aqueous core compartments. They can form spontaneously when amphipathic molecules aggregate in aqueous media to form bilalyer membranes of closed struc- tures with concentric lamellae [50-52]. The initial focus of liposome research was biochemical - liposomes were viewed as simple synthetic analogues of natural membranes, facilitating their use for studying cell membrane properties such as structure and fluidity. Since liposomes synthesized from naturally occurring phospholipids are biodegradable, nontoxic and nonimmunogenic, over the last couple of decades these vesicles have gained appreciation as useful cell delivery vehicles for both water- and lipid-soluble membrane-impermeant biomaterials [51, 53-55]. For example, they are used in the pharmaceutical and medical industry as drug carriers and controlled release systems for antitumor, antimicrobial and antiinflammatory agents in cancer, gene, arthritis, metal chelation and hemophilia therapies [52-61]. Another useful application of liposomes in these fields involve controlled delivery of diagnostic agents such as radiopharmaceutical markers and signal carriers [53, 54, 62]. In immunology, antigens, interleukins and cytokines encapsulated in liposomes are used as immunoadjuvants for vaccine development and as immunomodulators [52, 54, 63, 64]. Many other scientific disciplines have benefited from the applications of liposomes, including food and cosmetic industry, chemistry, genetic engineering, toxicology and ecology [65].

A similar trend can be seen in the biopreservation research. Crowe et al. [66-68] pioneered the use of liposomes as model membranes to study mechanisms by which trehalose protects cell membranes during lyophilization. Other investigators focused on liposomes as tools to characterize cell behavior during freezing, thawing and vitrification, ice propagation, phospholipid liquid crystalline-gel phase transition temperatures as well as the cryoprotective action of permeating and nonpermeating additive solutions [69-76]. Recently, liposomes have also been applied in the biopreservation field as means of improving cell recovery during freeze drying [7680]. A key study by Kheirolomoom et al. [80] reported that the membrane lesion caused by RBC lyophilization can be minimized by addition of liposomes to the lyophilization buffer. In this study, small unilamellar liposomes added to the lyophilization buffer preserved membrane integrity and reduced hemolysis of lyophilized RBCs [80]. This phenomenon was shown to be due to direct interactions between liposomes and RBC membranes, requiring vesicles of defined size and composition.

Our aim has been to incorporate liposome, preservation and transfusion medicine research to advance the science of $\mathrm{RBC}$ biopreservation. Our research approach is to focus on applications of liposomes as delivery tools. As biomechanically detrimental changes to the RBC membrane persist during the hypothermic storage in all current additive solutions, our research aimed to investigate liposome incorporation into $\mathrm{RBC}$ membranes as an effective approach for minimizing RBC hypothermic storage membrane lesion. With RBC cryopreservation, we have been focusing our research efforts on natural cryoprotectants such as trehalose. 
Trehalose, a nonreducing glucose disaccharide found at high concentrations in many species of anhydrobiotic organisms, shows significant promise in protecting cellular viability and structural integrity during freezing and desiccation. Unlike glycerol, trehalose is not toxic, and the concentrations required for cryoprotective effect have been shown to be significantly less $[47,48,81,82]$. Therefore, the introduction of intracellular trehalose would circumvent the necessity for the expensive and tedious deglycerolization procedure, resulting in cryopreserved RBCs available for transfusion immediately upon request. However, the RBC membrane's impermeability to trehalose provides a significant challenge. With RBC cryopreservation, our research has focused on investigating whether liposomal delivery can be used as a permeabilization strategy for the intracellular accumulation of trehalose with minimal injury to RBC membranes. In this review, we will summarize experimental results of our systematic studies investigating emerging liposomes in the RBC biopreservation.

\section{Interactions of Liposomes with Red Blood Cells}

Delineating the mechanism of liposomal interaction with RBCs is an important step towards establishing the plausibility of using liposomes as delivery tools for biopreservation purposes. A majority of the liposome-cell interaction studies to date have been performed in vitro to avoid the additional complexities of an in vivo system and have identified several modes of liposome-cell interaction: adsorption to cell membrane with or without lipid transfer, fusion with cells and endocytosis [83-86]. Adsorption is the association of intact liposomes with the cell membrane, without internalization. Liposomes can be loosely adsorbed to the cell membrane, in which case they can be removed by a simple wash, whereas tightly adsorbed liposomes require further processing to be released from the cell membrane [83, 84, 87]. Liposome adsorption is usually associated with the transfer of lipid molecules from the liposome membrane to the plasma membrane, without transfer of liposome aqueous contents [88]. Similar to lipid transfer, fusion implies merging of the liposome and cell lipid bilayers. However, membrane fusion requires at least three distinct processes: aggregation or binding of two membranes, the subsequent destabilization and merger of these membranes and, finally, mixing of the aqueous compartments [89, 90]. The final mode of liposome-cell interaction is endocytosis, which can be defined as the uptake of intact liposomes into endocytic vesicles. As mature RBCs are unable to endocytose [91], there are three possible outcomes: no interaction, liposome adsorption to RBC membranes, and delivery of liposomal aqueous contents through liposome fusion.

Our laboratory has adopted multiple techniques in liposomal research to synthesize and characterize liposomes for use in bipreservation. In 2007 [92] we described multiple methods to qualitatively and quantitatively assess synthesized liposomes, including size, concentration, morphology, population homogeneity, membrane composition and intraliposomal encapsulation. Use of liposomes as delivery vesicles requires a consistent and well characterized product, which is essential for controlled, reproducible and effective delivery of liposome contents to RBCs. In the follow-up paper [93], we described multiple studies delineating the mechanism of liposomal interaction with RBCs. To examine liposome interaction with RBCs, a lipid mixing assay based on fluorescence dequenching of R18 was used to monitor the merging of liposome-RBC membranes while 5(6)-CF marker was used to examine the intermixing of aqueous contents. In addition, liposomes synthesized in this study contained trehalose in their aqueous core. The results of the R18 dequenching assay demonstrated transfer of R18 marker from the membranes of trehalose-containing liposomes, shown by a marked increase of RBC fluorescence compared to liposomes. Density gradient separation results suggest that liposomes are adsorbing both loosely and tightly to RBC surface. Moreover, liposomal content delivery demonstrated by transfer of 5(6)-CF marker was confirmed by spectrophotometric measurement of trehalose in RBC cytosol. The results from this work, including fluorescence transfer and intracellular trehalose measurement, strongly support the hypothesis that liposomes can be used as delivery vesicles [93]. The presence of liposome-RBC membrane lipid mixing and content delivery indicates that the mechanism of interaction between unilamellar trehalose-containing liposomes and human RBCs involves adsorption of the vesicles to the RBC surface as well as liposome content incorporation through membrane fusion [93].

As experimental parameters have been shown to play a significant role in liposome-cell interaction and post-interaction cell viability, our next study investigated the effects of several experimental variables [94]. These variables include the composition of liposome membrane and aqueous core as well as the incubation conditions, such as liposome-to-cell ratio, incubation time, temperature, and medium on liposome-cell interaction, trehalose loading and RBC membrane quality. This work provided valuable experimental evidence for identifying conditions which enhance liposome interaction with RBCs, such as negative charge of liposome membrane, prolonged incubation time and higher incubation temperature. The results of this study also demonstrated that liposome treatment did not cause significant adverse effects on $\mathrm{RBC}$ membrane quality, which is critical if liposomes are to be used as a membrane permeabilization technique. RBC membrane damage was shown to be more dependent on the incubation time and temperature, rather than on liposome composition and concentration. Therefore, we proposed that improving liposome delivery involves balancing the efficiency of liposome uptake with the minimization of cell membrane injury resulting from prolonged liposome-cell incubation at higher temperatures. 


\section{Liposomes and Red Blood Cell Cryopreservation}

Studies of natural systems that survive extreme environmental stress, such as freezing and desiccation, have shown that one of the adaptive mechanisms is the accumulation of sugars such as trehalose [95-97]. The application of trehalose as a nonpermeating intracellular cryprotectant for RBC cryopreservation would circumvent the necessity for the expensive and tedious deglycerolization procedure, resulting in cryopreserved RBCs available for transfusion immediately upon request. However, for maximum protection efficiency, the presence of extracellular trehalose is not sufficient; trehalose presence is required on both sides of the cell membrane [44-49]. In addition to the well-described biostabilizing properties of trehalose, liposomes themselves have been shown to protect cells under stress conditions other than freezing. Recently, Kheirolomoom et al. [80] have demonstrated that membrane lesion caused by RBC lyophilization can be reduced by adding liposomes to the lyophilization buffer. During lyophilization and rehydration, RBC membranes lose phospholipids through microvesiculation, resulting in the deterioration of RBC membrane composition, morphology and rheology [80, 98, 99]. Small unilamellar liposomes added to the lyophilization buffer preserved membrane integrity and reduced hemolysis of lyophilized RBCs [80]. Liposomes were also used to reduce the chilling injury of bovine spermatozoa and oocytes [75]. As stress conditions are also associated with ice formation that accompanies low temperatures, the liposome incorporation into RBC membranes may provide an effective approach for reducing cell cryoinjury.

Our studies described in the previous section provided evidence that, under specific experimental conditions, trehalosecontaining liposomes can fuse with RBCs to deliver micromolar concentrations of trehalose to the cell cytosol, with minimal detrimental effects on RBC membrane quality [93, 94]. Our more recent work has focused on the effects of trehalosecontaining liposomes on the RBC response to freezing [100]. In this study we aimed to address several key questions, including:

- Does liposome treatment improve RBC recovery after freezing?

- What is the effect of different extracellular solutions and cooling rates on liposome-treated $\mathrm{RBC}$ response to freezing?

- Are the effects seen due to trehalose or membrane phospholipid delivery resulting from liposome fusion?

- What are the effects of freezing on liposome-treated RBC membrane quality?

We demonstrated that liposome treatment significantly improves recovery and membrane integrity of human RBCs following low temperature exposure [100]. Liposomes modulate the $\mathrm{RBC}$ freezing response, resulting in cell cryoprotection and, thus, behaving as a novel cryoprotectant. However, the mechanism underlying the liposome cryoprotective action remains unclear. The extent of liposome-RBC interaction was shown to play an essential role for cryoprotection as charged trehalose-containing liposomes were more effective at protecting RBCs against cryoinjury than uncharged liposomes. While both trehalose- and saline-containing liposomes improved RBC post-thaw recovery, there was no cryoprotection when negatively charged lipids in the free and multilamellar form were incubated with RBCs [100]. These results suggest that liposomes in the form of defined unilamellar vesicles are necessary to confer cryoprotection to RBCs. This study also demonstrated that different extracellular solutions and cooling rates play an important role in liposome cryoprotective effect. Liposome-treated RBCs showed an improved postthaw survival if higher cooling rates were applied and extracellular freezing solutions contained trehalose or liposomes. Furthermore, we provided important evidence that the liposome cryoprotective effect is not due to the delivery of intracellular trehalose, but is likely related to modification and/or preservation of the RBC membrane [100].

\section{Liposomes and Red Blood Cell Hypothermic Storage}

Precipitated by concerns over the detrimental clinical outcomes of transfusing in vitro stored RBCs, new approaches are needed to address the RBC hypothermic storage lesion. $\mathrm{RBC}$ membrane is a primary site of injury caused by in vitro storage of RBCs at hypothermic temperatures, involving membrane loss through microvesiculation. Various investigators have reported a range of $\mathrm{RBC}$ membrane lipid loss in different anticoagulant-additive solutions, from 13 to $30 \%$ of RBC phospholipids, over 6 weeks of hypothermic storage [4, $5,101]$. Lipid loss from the RBC membrane is balanced with respect to both cholesterol and phospholipid, through the blebbing of microvesicles from the tips of echinocytic spicules [4, 5, 101-103].

Our group has proposed to use liposomes to mitigate RBC hypothermic storage membrane lesion. Unlike nucleated cells, where membrane phospholipids participate in a state of dynamic equilibrium involving synthesis, transport and degradation, mature RBCs have no capacity to synthesize or actively regulate their phospholipid membrane composition [80, 104, 105]. Thus, supplementing phospholipids to the RBC membrane through liposome interaction might be important in efforts to improve RBC membrane quality during the hypothermic storage. Liposomes are nontoxic, non-immunogenic, and FDA-approved for human use $[53,106]$. Furthermore, liposomal delivery does not require specialized equipment, extensive cellular manipulations or specific technical expertise. Our studies on the effects of liposome treatment on $\mathrm{RBC}$ hypothermic storage lesion so far have focused on several key aspects: composition of RBC membranes and their thermal phase behavior after the interaction with liposomes as well as the effect of liposome treatment on RBC membrane 
deformability, an essential RBC quality parameter for in vivo hemorheology and oxygen delivery [107-110].

The thermal phase behavior of RBC membranes is an important factor to consider in examining the effect of liposome interaction with RBCs. The conformational state of RBC membrane, and therefore membrane fluidity, is affected by the phospholipid, cholesterol and protein composition. At physiological temperatures, RBC membranes are structured in the lamellar liquid crystalline phase, with the acyl chains relatively disordered, whereas more orderly lamellar gel phase occurs when RBCs are stored hypthermically. In another study [110] we examined the effects of liposomes composed of a homologous series of linear saturated phosphatidylcholine phospholipids on RBC membrane fluidity using Fourier transform infrared spectroscopy, matrix-assisted laser desorption/ionizatin mass spectrometry and colorimetric assays. This study establishes that liposomes alter RBC membrane properties by cholesterol depletion and lipid addition, with liposomes composed of short acyl chain length lipids causing an increase in RBC membrane conformational disorder at suprazero temperatures while long acyl chain length lipids were found to have little effect on RBC membrane conformational disorder [110].

In addition to investigating the effect of liposome interaction on RBC membrane fluidity, our studies had focused on another important RBC membrane parameter - deformability. RBC deformability is essential for RBCs maintaining the ability to bend at variable shear stresses to ensure the successful delivery of oxygen to the tissues. Ektacytometry has previously been used to assess RBC deformability in the basic research context, but, due to difficult data analysis, no method has been routinely used to monitor RBC deformability changes occurring during ex vivo hypothermic storage.

In 2010 [107, 108] we described an alternative method to conventional ektacytometry analysis by employing an EadieHofstee linear data transformation and demonstrated its applicability to the deformation analysis of hypothermically stored RBCs. This requires plotting the elongation index versus elongation index/shear stress, followed by calculation of the $\mathrm{y}$-intercept and slope $($ slope $=-\mathrm{KEI}$, yint $=$ EImax $)$. EImax is defined as the maximum theoretical elongation index while KEI is the shear stress required to produce $1 / 2$ of the EImax. To test the sensitivity of this technique, packed RBCs stored hypothermically for less than 5 days were treated with three agents previously shown to modify the RBC membrane and/or cytoskeleton: tert-butyl hyrdroperoxide ( $\mathrm{t}-\mathrm{BuOOH}), \mathrm{H}_{2} \mathrm{O}_{2}$ or methyl $\beta$-cyclodextrin. RBCs were analyzed via ektacytometry at shear stresses ranging from 0.95 to $30 \mathrm{~Pa}$. RBC elongation data was analyzed using a traditional approach and the Eadie-Hofstee transformation method. To investigate the effect of hypothermic storage on RBC deformability, leukoreduced packed RBC units stored in SAGM additive solution at $4{ }^{\circ} \mathrm{C}$, sampled weekly for 49 days and assayed for cellular elongation, were used.
The results of this study demonstrate that Eadie-Hofstee transformation of RBC elongation data is an effective and sensitive method for quantifying RBC cellular deformability [107, 108]. Although traditional elongation index analysis demonstrated dose-dependent decreases in RBC elongation with all agents, Eadie-Hofstee data transformation gave insight into the kinetics of this process. In the cases of $\mathrm{t}-\mathrm{BuOOH}$ and $\mathrm{H}_{2} \mathrm{O}_{2}$, EImax values remained nearly constant with increased dosage; however, KEI values increased significantly. In contrast, treatment with methyl $\beta$-cyclodextrin resulted in sharply decreasing EImax values. We were also able to demonstrate significant decreases in deformability (EImax) of hypothermically stored RBCs. Hypothermically RBCs also appeared to have more rigid membranes, as demonstrated by a decrease in KEI values [107, 108].

Most recently we have examined the effect of liposome treatment on RBC membrane quality during hypothermic storage [107]. Similarly to our previous studies, unilamellar liposomes were synthesized via an extrusion method to contain cholesterol, saturated and unsaturated phospholipids, and then incubated with RBCs. RBC membrane quality was assessed by percent hemolysis and membrane deformability. Each RBC quality parameter was measured immediately following liposome incubation and throughout a 42-day storage period. The results showed that RBC membranes react differently to liposomes with varied fatty acid compositions. As expected, the percent hemolysis of all RBC-liposome compositions increased with storage time compared to baseline values. However, after 42 days of storage, this increase was much more dramatic with RBCs incubated with liposomes containing phospholipids with higher degree of unsaturation and shorter acyl chain length. RBC membrane deformability also decreased gradually during the hypothermic storage. However, membranes of RBCs treated with liposomes containing phospholipids with saturated acyl chains were observed to better maintain membrane deformability during the hypothermic storage. The mechanism of this action warrants further research. We believe that future investigations into the optimal liposome composition will result in effective liposome-based strategies to combat the membrane component of the RBC hypothermic storage lesion.

\section{Conclusion}

Every year, millions of RBC units are transfused worldwide due to the application of biopreservation techniques to transfusion medicine. However, deterioration of RBC quality and function during the hypothermic storage and the expensive, labor-intensive nature of glycerol-based RBC cryopreservation techniques have left much room for improvement. This review summarizes emerging research into using liposomes to improve the quality of in vitro stored RBCs, both relating to hypothermic storage and cryopreservation. Integration of 
current biopreservation research with blood banking practices offers enormous potential for future improvements of safety and efficacy of RBC transfusion.

\section{Disclosure Statement}

The authors declared no conflict of interest.

\section{References}

1 Walker RH (ed): American Association of Blood Banks Technical Manual. 11 ed. Bethesda, MD: American Association of Blood Banks; 2006.

$\checkmark 2$ Tinmouth A, Chin-Yee I: The clinical consequences of the red cell storage lesion. Transfus Med Rev 2001;15:91-107.

3 Scott KL, Lecak J, Acker JP: Biopreservation of red blood cells: past, present and future. Transfus Med Rev 2005;19:127-142.

4 Wolfe LC: The membrane and the lesions of storage in preserved red blood cells. Transfusion 1985; 25:185-203.

5 Hess JR: An update on solutions for red cell storage. Vox Sang 2006;91:13-19.

6 Bessos H, Seghatchian J: Red cell storage lesion: the potential impact of storage-induced CD47 decline on immunomodulation and the survival of leucofiltered red cells. Transfus Apher Sci 2005;32: 227-232.

$>7$ Bratosin D, Mazurier J, Tissier JP, Estaquier J, Huart JJ, Ameisen JC, et al: Cellular and molecular mechanisms of senescent erythrocyte phagocytosis by macrophages. Biochimie 1998;80:173-195.

8 Hogman CF, Meryman HT: Storage parameters affecting red blood cell survival and function after transfusion. Transfus Med Rev 1999;13:275-296.

-9 Maharshak N, Arbel Y, Shapira I, Berliner S, BenAmi R, Yedgar S, et al: Increased strength of erythrocyte aggregates in blood of patients with inflammatory bowel disease. Inflamm Bowel Dis 2009;15: 707-713.

10 Relevy H, Koshkaryev A, Manny N, Yedgar S, Barshtein G: Blood banking-induced alteration of red blood cell flow properties. Transfusion 2008;48: 136-146.

11 Chin-Yee I, Arya N, d'Almeida MS: The red cell storage lesion and its implication for transfusion. Transfus Sci 1997;18:447-458.

12 Stewart A, Urbaniak S, Turner M, Bessos H: The application of a new quantitative assay for the monitoring of integrin-associated protein CD47 on red blood cells during storage and comparison with the expression of CD47 and phosphatidylserine with flow cytometry. Transfusion 2005;45:1496-1503.

13 Kurup PA, Arun P, Gayathri NS, Dhanya CR, Indu AR: Modified formulation of CPDA for storage of whole blood, and of SAGM for storage of red blood cells, to maintain the concentration of 2,3-diphosphoglycerate. Vox Sang 2003;85:253-261.

14 Hess JR, Greenwalt TG: Storage of red blood cells: new approaches. Transfus Med Rev 2002;16:283295.

15 Hovav T, Yedgar S, Manny N, Barshtein G: Alteration of red cell aggregability and shape during blood storage. Transfusion 1999:39:277-281.

$\checkmark 16$ Berezina TL, Zaets SB, Morgan C, Spillert CR, Kamiyama M, Spolarics Z, et al: Influence of storage on red blood cell rheological properties. J Surg Res 2002;102:6-12.

17 Rous P, Turner JR: The preservation of living red blood cells in vitro I. Methods of preservation. J Exp Med 1916;23:219-237.

18 Holme S: Current issues related to the quality of stored RBCs. Transfus Apher Sci 2005;33:55-61.
Hogman CF: Recent advances in the preparation and storage of red cells. Vox Sang 1994;67:243-246.

20 Beutler E, Kuhl W: Volume control of erythrocytes during storage: the role of mannitol. Transfusion 1987;28:353-357.

21 Hess JR, Lippert LE, Derse-Anthony CP, Hill HR, Oliver CK, Rugg N, et al: The effects of phosphate, $\mathrm{pH}$, and AS volume on RBCs stored in salineadenine-glucose-mannitol solutions. Transfusion 2000;40:1000-1006.

22 Vamvakas EC, Moore SB: Confounding and the effects of allogeneic transfusion on survival (letter to the editor). Vox Sang 1995;69:142-143

23 Mynster T, Nielsen H: The impact of storage time of transfused blood on postoperative infectious complications in rectal cancer surgery. Scand J Gastroenterol. 2000;35:212-217.

24 Johnson JL, Moore EE, Kashuk JL, Banerjee A, Cothren CC, Biffl WL, et al: Effect of blood products transfusion on the development of postinjury multiple organ failure. Arch Surg 2010;145:973-977.

25 Aiboshi J, Moore EE, Ciesla DJ, Silliman CC: Blood transfusion and the two-insult model of post-injury multiple organ failure. Shock 2001;15:302-306.

26 Skanberg J, Lundholm K, Haglind E: Effects of blood transfusion with leucocyte depletion on length of hospital stay, respiratory assistance and survival after curative surgery for colorectal cancer. Acta Oncol 2007;46:1123-1130.

27 Vamvakas EC, Carven JH: RBC transfusion and postoperative length of stay in the hospital or the intensive care unit among patients undergoing coronary artery bypass graft surgery: the effects of confounding factors. Transfusion 2000;40:832-839.

28 Kipps AK, Wypij D, Thiagarajan RR, Bacha EA, Newburger JW: Blood transfusion is associated with prolonged duration of mechanical ventilation in infants undergoing reparative cardiac surgery. Pediatr Crit Care Med. 2011;12:52-56.

29 Twomley K, Rao S, Becker R: Proinflammatory, immunomodulating, and prothrombotic properties of anemia and red blood cell transfusions. J Thromb Thrombolysis. 2006;21:167-174.

30 Tinmouth A, Fergusson D, Yee IC, Hebert PC: Clinical consequences of red cell storage in the critically ill. Transfusion 2006;46:2014-2027.

31 Elfath MD: Is it time to focus on preserving the functionality of red blood cells during storage? Transfusion. 2006;46:1469-1470.

32 Ho J, Sibbald WJ, Chin-Yee IH. Effects of storage on efficacy of red cell transfusion: when is it not safe? Crit Care Med 2003;31(12 suppl):S687-697.

33 Vamvakas EC: Meta-analysis of clinical studies of the purported deleterious effects of 'old' (versus 'fresh') red blood cells: are we at equipoise? Transfusion 2010;50:600-610.

34 Beutler E: Back to the future in RBC preservation. Transfusion 2000;40:893-895.

35 Luyet B, Rapatz G: A review of basic researches on the cryopreservation of red blood cells. Cryobiology 1970;6:425-482.

36 Meryman HT, Hornblower M. A method for freezing and washing red blood cells using a high glycerol concentration. Transfusion 1972;12:145-156.
Rowe AW, Eyster E, Keellner A: Liquid nitrogen preservation of red blood cells for transfusion. Cryobiology 1968;5:119-128.

38 Valeri CR, Runck AH: Long term frozen storage of human red blood cells: studies in vivo and in vitro of autologous red blood cells preserved up to six years with high concentration of glycerol. Transfusion 1969;9:5-14.

39 Valeri CR, Ragno G, Pivacek LE, Cassidy GP, Srey R, Hansson-Wicher M, et al: An experiment with glycerol-frozen red blood cells stored at -80 degrees C for up to 37 years. Vox Sang 2000;79:168-174.

40 Valeri CR, Pivacek LE, Cassidy GP, Ragno G: In vitro and in vivo measurements of human RBCs frozen with glycerol and subjected to various storage temperatures before deglycerolization and storage at 4 degrees $\mathrm{C}$ for 3 days. Transfusion 2001; 41:401-405.

41 Valeri CR: Status report on the quality of liquid and frozen red blood cells. Vox Sang 2002;83 (suppl 1):193-196.

42 Umlas J, Jacobson M, Kevy SV: Suitable survival and half-life of red cells after frozen storage in excess of 10 years. Transfusion 1991;31:648-649.

43 Fuller BJ, Lane N, Benson EE (eds): Life in the Frozen State. Danvers, CRC Press Web, 2004.

44 Acker JP, Lu XM, Young V, Cheley S, Bayley H, Fowler A, et al: Measurement of trehalose loading of mammalian cells porated with a metal-actuated switchable pore. Biotechnol Bioeng 2003;82:525532.

45 Buchanan SS, Gross SA, Acker JP, Toner M, Carpenter JF, Pyatt DW: Cryopreservation of stem cells using trehalose: evaluation of the method using a human hematopoietic cell line. Stem Cells Dev 2004:13:295-305.

46 de-Araujo P: The role of trehalose in cell stress. Braz J Med Biol Res 1996;29:873-875.

47 Eroglu A, Russo MJ, Bieganski R, Fowler A, Cheley S, Bayley H, et al: Intracellular trehalose improves the survival of cryopreserved mammalian cells. Nat Biotechnol 2000;18:163-167.

48 Eroglu A, Toner M, Toth TL: Beneficial effect of microinjected trehalose on the cryosurvival of human oocytes. Fertil Steril 2002;77:152-158.

-49 Kikawada T, Saito A, Kanamori Y, Nakahara Y, Iwata K-i, Tanaka D, et al: Trehalose transporter 1, a facilitated and high-capacity trehalose transporter, allows exogenous trehalose uptake into cells. Proc Natl Acad Sci U S A 2007;104:11585-11590.

50 Bangham AD, Standish MM, Watkins JC: Diffusion of univalent ions accross the lamellae of swollen phospholipids. J Mol Biol 1965;13:238-252.

51 Philippot JR, Schuber F: Liposomes as Tools in Basic Research and Industry. Boca Raton, CRC Press, 1995.

52 Lasic DD: The mechanism of vesicle formation. Biochem J 1988;256:1-11.

53 Banerjee R: Liposomes: applications in medicine. J Biomater Appl 2001;16:3-21.

54 Chonn A, Cullis PR: Recent advances in liposomal drug-delivery systems. Curr Opin Biotechnol 1995; 6:698-708. 
55 Poste G, Papahadjopoulos D, Vail WJ: Lipid vesicles as carriers for introducing biologically active materials into cells. Methods Cell Biol 1976;14: 33-71.

56 Andresen TL, Jensen SS, Jorgensen K: Advanced strategies in liposomal cancer therapy: problems and prospects of active and tumor specific drug release. Prog Lipid Res 2005;44:68-97.

57 Wasan KM, Lopez-Berestein G: The past, present and future uses of liposomes in treating infectious diseases. Immunopharmacol Immunotoxicol 1995;17:1-15.

-58 Metselaar JM, Wauben MH, Wagenaar-Hilbers JP, Boerman OC, Storm G: Complete remission of experimental arthritis by joint targeting of glucocorticoids with long-circulating liposomes. Arthritis Rheum 2003;48:2059-2066.

59 Mikaelsson M, Oswaldsson U: Assaying the circulating factor VIII activity in hemophilia A patients treated with recombinant factor VIII products. Semin Thromb Hemost 2002;28:257-264

60 Rahman YE: Potential of the liposomal approach to metal chelation therapy. Front Biol 1979;48:625652.

-61 Zabner J, Fasbender AJ, Moninger T, Peollinger KA, Welsh MJ: Cellular and molecular bariers to gene transfer by a cationic lipid. J Biol Chem 1995; 270:18997-19007.

62 Bloch SH, Dayton PA, Ferrara KW: Targeted imaging using ultrasound contrast agents. Progess and opportunities for clinical and research applications. IEEE Eng Med Biol Mag 2004;23:18-29.

-63 Tan PH, Beutelspacher SC, Wang YH, McClure MO, Ritter MA, Lombardi G, et al: Immunolipoplexes: an efficient, nonviral alternative for transfection of human dendritic cells with potential for clinical vaccination. Mol Ther 2005;11:790-800.

64 Bergers JJ, Den Otter W, Dullens HF, Kerkvliet CT, Crommelin DJ: Interleukin-2-containing liposomes: interaction of interleukin-2 with liposomal bilayers and preliminary studies on application in cancer vaccines. Pharm Res 1993;10:1715-1721.

65 Torchillin VP, Weissig V (eds): Liposomes: A Practical Approach, 2nd ed. Boston, Oxford University Press, 2003.

66 Crowe JH, Crowe LM, Carpenter JF, Rudolph AS, Wistrom CA, Spargo BJ, et al: Interactions of sugars with membranes. Biochim et Biophys Acta 1988;947:367-384.

67 Crowe LM, Crowe JH, Rudolph A, Womersley C, Appel L: Preservation of freeze-dried liposomes by trehalose. Arch Biochem Biophys 1985;242:240-247.

68 Crowe LM, Womersley C, Crowe JH, Reid D, Appel L, Richards AB: Prevention of fusion and leakage in freeze-dried liposomes by carbohydrates. Biochim Biophys Acta 1986;861:131-140.

69 Callow RA, McGrath JJ. Thermodynamic modeling and cryomicroscopy of cell-size, unilamellar, and paucilamellar liposomes. Cryobiology 1985;22: 251-267.

70 Anchordoguy TJ, Rudolph AS, Carpenter JF, Crowe JH: Modes of interaction of cryoprotectants with membrane phospholipids during freezing. Cryobiology 1987;24:324-331.

71 Anchordoguy TJ, Cecchini CA, Crowe JH, Crowe LM: Insights into the cryoprotective mechanism of dimethyl sulfoxide for phospholipid bilayers. Cryobiology 1991;28:467-473.

72 Kristiansen J: Leakage of a trapped fluorescent marker from liposomes: effects of eutectic crystallization of $\mathrm{NaCl}$ and internal freezing. Cryobiology 1992;29:575-584.
73 Crowe JH, Leslie SB, Crowe LM: Is vitrification sufficient to preserve liposomes during freeze-drying? Cryobiology 1994;31:355-366.

74 Tomczak MM, Vigh L, Meyer JD, Manning MC, Hincha DK, Crowe JH: Lipid unsaturation determines the interaction of AFP type I with model membranes during thermotropic phase transitions. Cryobiology 2002;45:135-142.

75 Zeron Y, Tomczak M, Crowe J, Arav A: The effect of liposomes on thermotropic membrane phase transitions of bovine spermatozoa and oocytes: implications for reducing chilling sensitivity. Cryobiology 2002;45:143-152.

76 Siow LF, Rades T, Lim MH: Characterizing the freezing behavior of liposomes as a membrane model system. Cryobiology 2007;55:210-221.

77 Holovati JL, Gyongyossy-Issa M, Acker JP: Liposome-delivered intracellular trehalose improves recovery of frozen red blood cells. Cryobiology 2007;55:333.

78 Shirakashi R, Yamauchi K, Reuss R, Zimmermann U, Sukhorukov VL: Electrofusion of Jurkat cells and giant unilamelar liposomes loaded with trehalose. Cryobiology 2006;53:397.

79 Scott KL, Gyongyossy-Issa MIC, Acker JP. Response of hematopoietic progenitor cells to trehalose-loaded liposomes. Cryobiology 2006;53:380.

80 Kheirolomoom A, Satpathy GR, Torok Z, Banerjee M, Bali R, Novaes RC, et al: Phospholipid vesicles increase the survival of freeze-dried human red blood cells. Cryobiology 2005;51:290-305.

81 Eroglu A: Progressive elimination of microinjected trehalose during mouse embryonic development. Reprod Biomed Online 2005;10:503-510.

82 Buchanan SS, Menze M, Hand S, Pyatt DW, Carpenter JF: Cryopreservation of human hematopoietic stem and progenitor cells loaded with treahlose: transient permeablilization via the adenosine triphosphate-dependent $\mathrm{P} 2 \mathrm{Z}$ receptor channel. Cell Preserv Technol 2005;4:212-222.

83 Pagano RE, Huang L: Interaction of phospholipid vesicles with cultured mammalian cells: studies of mechanism. J Cell Biol 1975;67:49-60.

84 Batzri S, Korn ED: Interaction of phospholipid vesicles with cells: endocytosis and fusion as alternate mechanisms for the uptake of lipid-soluble and water-soluble molecules. J Cell Biol 1975;66:621-634.

85 Huang L, Ozato K, Pagano RE: Interactions of phospholipid vesicles with murine lymphocytes: vesicle-cell adsorption and fusion as alternate pathways of uptake. Membr Biochem 1978;1:1-26.

86 Pagano RE: Interactions of liposomes with mammalian cells. Annu Rev Biophys Bioeng 1978;7: 435-468.

87 Pagano RE, Takeichi M: Adhesion of phospholipid vesicles to chinese hamster fibroblasts. J Cell Biol 1977;74:531-546.

88 Martin JF, MacDonald RC: Lipid vesicle-cell interactions. Introduction of a new antigenic determinant into erythrocyte membranes. J Cell Biol 1976;70:515-523.

89 Tamm LK, Crane J, Kiessling V: Membrane fusion: a structural perspective on the intrplay of lipids and proteins. Curr Opin Struct Biol 2003;13:453-466.

90 Prestegard JH, O’Brien MP: Membrane and vesicle fusion. Annu Rev Phys Chem 1987;38:383-411.
91 Harmening DM: The red blood cell: structure and function; in Harmening DM (ed): Clinical Hematology and Fundamentals of Hemostasis, 3rd ed. Philadelphia, F.A. Davis, 1997, pp 54-71.

92 Holovati JL, Acker JP: Spectrophotometric measurement of intraliposomal trehalose. Cryobiology 2007;55:98-107.

93 Holovati JL, Gyongyossy-Issa MI, Acker JP: Investigating interactions of trehalose-containing liposomes with human red blood cells. Cell Preserv Technol 2008;6:133-146.

94 Holovati JL, Gyongyossy-Issa MI, Acker JP. Effect of liposome charge and composition on the delivery of trehalose into red blood cells. Cell Preserv Technol 2008;6:207-218.

95 Crowe JH, Crowe LM: Preservation of membrane in anhydrobiotic organisms: the role of trehalose. Science 1984;223:701-703.

96 Crowe JH, Crowe LM: Preservation of mammalian cells-learning nature's tricks. Nat Biotechnol 2000;18:145-146.

97 Crowe JH, Crowe LM, Wolkers WF, Oliver AE, Ma X, Auh JH, et al: Stabilization of dry mammalian cells: lessons from nature. Integr Comp Biol 2005;45:810-820

-98 Torok Z, Satpathy GR, Banerjee M, Bali R, Little E, Novaes RC, et al: Preservation of trehaloseloaded red blood cells by lyophilization. Cell Preserv Technol 2005;3:96-111.

99 Sowemimo-Coker SO, Goodrich RP, Zerez CR, Tanaka KR: Refrigerated storage of lyophilized and rehydrated, lyophilized human red cells. Transfusion 1993;33:322-329.

100 Holovati JL, Gyongyossy-Issa MI, Acker JP Effects of trehalose-loaded liposomes on red blood cell response to freezing and post-thaw membrane quality. Cryobiology 2009;58:75-83.

101 Greenwalt TJ: The how and why of exocytic vesicles. Transfusion 2006;46:143-152.

102 Draper CJ, Greenwalt TJ, Dumaswala UJ: Biochemical and structural changes in RBCs stored with different plasticizers: the role of hexanol. Transfusion 2002;42:830-835.

103 Haradin AR, Weed RI, Reed CF: Changes in physical properties of stored erythrocytes. Transfusion 1969;9:229-237.

104 Stuart J: Erythrocyte rheology. J Clin Pathol 1985; 38:965-977.

105 Klinken SP: Red blood cells. Int J Biochem Cell Biol 2002;34:1513-1518.

106 Lasic DD. Novel applications of liposomes. Trends Biotechnol 1998;16:307-321.

107 Stadnick H, Stoll C, Holovati JL, Wolkers WF, Acker JP: Application of liposomes to improve the hypothermic storage of red blood cells. Vox Sang 2010;99(suppl 1):67-68.

108 Stadnick H, Onell R, Acker JP, Holovati JL: Eadie-Hofstee analysis of red blood cell deformability. Microcirc Hemorheol 2010;47:1-11.

109 Stadnick H, Acker JP, Holovati JL. Eadie-Hofstee analysis of ektocytometric deformability data from hypothermically stored red blood cells. Cryobiology. 2010;61:390.

110 Stoll C, Stadnick H, Kollas O, Holovati JL, Glasmacher B, Acker JP, et al: Liposomes alter thermal phase behavior and composition of red blood cell membranes. Biochim Biophys Acta 2011; 1808:474-481. 